\title{
Impact of Post Hepatitis C Chronic Liver Disease and Hepatocellular Carcinoma on Health Related Quality of Life
}

\author{
Somaia M. Ebeid ${ }^{1}$, Safaa H. Ali' ${ }^{1}$, Heba Y. Kamel ${ }^{1 *}$, Ahmed A. Elbaz², Hazem M. El-Hariri ${ }^{3}$ \\ ${ }^{1}$ Departments of Geriatric Medicine, Faculty of Medicine, Ain Shams University, Cairo, Egypt \\ ${ }^{2}$ Departments of Tropical Medicine, Faculty of Medicine, Ain Shams University, Cairo, Egypt \\ ${ }^{3}$ Department of Community Medicine Research, National Research Center, Cairo, Egypt \\ Email: "heba_youssif@yahoo.com
}

Received 4 October 2015; accepted 1 November 2015; published 4 November 2015

Copyright (C) 2015 by authors and Scientific Research Publishing Inc.

This work is licensed under the Creative Commons Attribution International License (CC BY). http://creativecommons.org/licenses/by/4.0/

(c) (i) Open Access

\section{Abstract}

Background: Post hepatitis C virus chronic liver disease (CLD) is prevalent among the Egyptian population with a bad impact upon their quality of life (QOL). Hepatocellular carcinoma (HCC) is one of the long term and fatal complications of CLD and it also has its negative impact on patient's quality of life. Aim: To assess impact of CLD and HCC on the quality of life of group of hospitalized elderly patients. Methodology: Ninety elderly patients were divided into three groups: 30 elderly with post hepatitis C virus CLD, 30 elderly with HCC and 30 others free of liver disease as control group (Cn), all were recruited from the in-patient ward and the outpatient clinic of the Geriatric Department, Ain-Shams University Hospital. After giving consent, comprehensive geriatric assessment was done with assessment of their quality of life by using the Short Form-36 health survey (SF-36). Investigations including liver enzymes, serum albumin, serum bilirubin and abdominal ultrasound were done. Results: All QOL domains were the highest among control group, followed by HCC group and the least among CLD group. The differences were statistically significant in most subscales and total score [Mean of $C n=81.9 \pm 12.4$, Mean of CLD $=47.5 \pm 21.9$, Mean of HCC $=62.3 \pm 16.1 ; \mathrm{P} \mathrm{Cn} / \mathrm{CLD} \leq 0.001, \mathrm{P} \mathrm{Cn} / \mathrm{HCC} \leq 0.001, \mathrm{P}$ CLD/HCC $=0.004]$. Albumin was the only biochemical marker correlated positively with total SF score and two subscales (PF and EF) $[r=0.408$; $P=0.025]$. Conclusion \& Recommendation: Our study showed a decrease in the QOL of Egyptian post hepatitis $C$ virus CLD and HCC patients compared with Egyptian population norms. The results showed that CLD were more affected than HCC patients. This had a particularly serious negative impact on their life. The findings indicate a need for updated counseling and educational materials designed to provide adequate information and consistent healthcare service to this patient setting.

\footnotetext{
${ }^{*}$ Corresponding author.
}

How to cite this paper: Ebeid, S.M., Ali, S.H., Kamel, H.Y., Elbaz, A.A. and El-Hariri, H.M. (2015) Impact of Post Hepatitis C Chronic Liver Disease and Hepatocellular Carcinoma on Health Related Quality of Life. Advances in Aging Research, 4, 177-186. http://dx.doi.org/10.4236/aar.2015.46019 


\section{Keywords}

\section{Post Hepatitis C Virus Chronic Liver Diseases, Hepatocellular Carcinoma, Quality of Life, Short Form-36 Health Survey}

\section{Introduction}

In 1947, the World Health Organization expanded the definition of health to include not only the absence of disease but also a complete state of physical, mental, and social well-being [1]-[3]. So it is important to know and assess the impact of disease on patient's health, society and on biomedical, physiological and socioeconomic outcomes. Quality of Life (QOL) has now attained important status in clinical patient management. The importance of impact of healthcare interventions on patient's everyday life is increasingly recognized rather than on patient's health alone [4].

The Short Form-36 (SF-36) health survey is a generic health status measurement consisting of 36 items in eight domains, which has demonstrated good reliability and validity in chronic disease populations, including patients with chronic liver diseases [5]-[8].

Viral liver diseases are common endemic diseases in Egypt. Both chronic liver diseases with or without cirrhosis are complications of viral liver diseases. Among patients with chronic liver disease, impairment in QOL has been reported [5]-[11]. Studies of chronic liver disease have consistently shown that QOL is significantly poorer in both cirrhotic and non-cirrhotic patients than healthy controls [12].

Hepatocellular carcinoma (HCC) is the most common primary liver cancer. It is the 5th most common cancer worldwide and the 3rd leading cause of cancer-related deaths [13] [14] and one of the major sequelae of chronic liver diseases. It is now increasing worldwide [15] [16] and the QOL of patients with HCC is an area of interest [17]-[19].

Given the time course of the disease and the burden of treatment, there are increasing concerns about healthrelated quality of life (HRQOL) associated with liver diseases and HCC [20]; therefore the aim of this study is to assess the impact of post hepatitis C virus chronic liver disease and HCC on quality of life of hospitalized elderly patients.

\section{Patients and Methods}

\subsection{Ethics}

This study had the approval of the ethics committee of the Ain Shams Faculty of Medicine. All subjects consented to participate in the study.

\subsection{Study Design}

Case control study.

\subsection{Patient Selection}

Ninety elderly patients were recruited from the in-patient ward, of the Geriatric Department, Ain Shams University Hospital, and they were divided into three groups:

Group 1: Thirty elderly patients free of hepatic diseases, they were considered as the control group (Cn).

Group 2: Thirty elderly patients with diagnosis of post hepatitis $C$ virus chronic liver disease (CLD). The diagnosis of chronic viral hepatitis $\mathrm{C}$ was based on a positive hepatitis $\mathrm{C}$ antibody (ELISA II analysis), with or without HCV RNA as detected by polymerase chain reaction [21]. No antiviral treatment was received.

Group 3: Thirty elderly patients with diagnosis of HCC on top of post hepatitis C virus chronic liver disease, according to the American Association for the Study of Liver Disease criteria [22] were informed of the diagnosis. None of the patients were actively receiving treatments for the CLD or HCC.

Patients with active bleeding, bacterial infection, or other acute events were studied after the complete resolution of the intervening complication. Patients with overt encephalopathy were excluded to prevent incorrect fill- 
ing of questionnaires. Patients with significant uncontrolled disorders, such as non-hepatic organ failure and depression, which can affect quality of life, were also excluded.

\subsection{Data Collection}

At admission, each patient gave informed consent and then extensive demographic and clinical data were also collected at this time. Patients' baseline characteristics, including age, gender, and marital statuses were collected. Laboratory data including alanine and aspartate aminotransferases, total bilirubin and serum albumin were collected.

\subsection{QOL Survey}

Short Form-36 health survey (SF-36) is composed of 36 questions, each of which was categorized into one of the eight domains: physical functioning (PF), bodily pain (P), role limitations due to physical health problems (RLPH), role limitations due to personal or emotional problems (RLEP), emotional well-being (EW), social functioning (SF), energy/fatigue (EF), and general health perceptions (GH). It also includes a single item that provides an indication of perceived change in health. These 36 items, presented here, are identical to the MOS SF-36 described before [23]. They were adapted from longer instruments completed by patients participating in the Medical Outcomes Study (MOS), an observational study of variation in physician practice styles and patient outcomes in different systems of health care delivery [24] [25].

Participants completed the self-administered QOL questionnaire: Short Form36 (SF-36 v2 Arabic version), a widely used and validated generic HRQOL questionnaire. We used the Arabic version of SF-36, which was translated by Al Abdulmohsin [26] whose results provide support for the reliability and equivalence of both the Arabic and English versions. This Arabic version is referred to as RAND 36-item health survey 1.0. The SF-36 was administered by self-administration or face-to-face interviews (for illiterate persons or those with other difficulties).

Generic measures provide comparisons between general populations and patients with chronic conditions, whereas disease-specific measures assess disease-specific symptoms and can capture patients' experiences throughout the course of a disease and its treatment [27]. The Short Form-36 Questionnaire (SF-36) is one tool commonly used as a generic measure to assess HRQOL.

\subsection{Statistical Methods}

The collected data were coded, tabulated, and statistically analyzed using IBM SPSS statistics (Statistical Package for Social Sciences) software version 22.0, IBM Corp., Chicago, USA, 2013. Descriptive statistics were done for quantitative data as mean \pm SD (standard deviation) and minimum \& maximum of the range for quantitative parametric data, while it was done for qualitative data as number and percentage. Inferential analyses were done for quantitative variables using independent t-test in cases of two independent groups with parametric data. In qualitative data, inferential analyses for independent variables were done using Chi square test for differences between proportions. The level of significance is taken at $\mathrm{P}$ value $<0.05$ is significant, otherwise is non-significant.

\section{Results}

\subsection{Demographic Data}

The characteristics of the study population are summarized (Table 1). The study groups were matched for age and sex. The population consisted of 51 (56\%) males and 39 (44\%) females, and the age of patients ranged from 60 to 90 years old (median 65). Mean duration of CLD was $12 \pm 7.5$ years (mean \pm SD; range, 5 - 20years), while mean duration of HCC was $13.1 \pm 11.9$ months (mean \pm SD; range, 3 - 36 months). Co-morbidities like hypertension (HTN), ischemic heart disease (ISHD), old stroke and chronic obstructive pulmonary disease (COPD) were significantly prevalent in both CLD and HCC groups.

\subsection{QoL Domains}

As regard comparison between study groups regarding QOL domains shows that all QOL domains were highest among control group, followed by HCC group and least among CLD group. The differences were statistically 
significant in most subscales and total score (Table 2 and Figure 1).

Table 1. Comparison between study groups regarding demographic characteristics, co-morbidities and laboratory findings.

\begin{tabular}{|c|c|c|c|c|c|c|c|}
\hline Variable & Measure & $\begin{array}{l}\text { Control } \\
(\mathrm{N}=\mathbf{3 0})\end{array}$ & $\begin{array}{c}\text { CLD } \\
(\mathrm{N}=\mathbf{3 0})\end{array}$ & $\begin{array}{c}\text { HCC } \\
(\mathrm{N}=30)\end{array}$ & P Cn/CLD & P Cn/HCC & P CLD/HCC \\
\hline \multirow{2}{*}{ Age (years) } & Mean \pm SD & $64.3 \pm 3.9$ & $64.9 \pm 5.1$ & $66.1 \pm 5.9$ & \multirow{2}{*}{$0.594^{\#}$} & \multirow{2}{*}{$0.161^{\#}$} & \multirow{2}{*}{$0.404^{\#}$} \\
\hline & Range & $60.0-74.0$ & $60.0-80.0$ & $60.0-90.0$ & & & \\
\hline \multirow{2}{*}{ Sex } & Male & $15(50.0 \%)$ & $19(63.3 \%)$ & $17(56.7 \%)$ & \multirow{2}{*}{$0.297^{\wedge}$} & \multirow{2}{*}{$0.605^{\wedge}$} & \multirow{2}{*}{$0.598^{\wedge}$} \\
\hline & Female & $15(50.0 \%)$ & $11(26.7 \%)$ & $13(43.3 \%)$ & & & \\
\hline \multirow{2}{*}{ Marital } & Married & $20(60.0 \%)$ & $24(80.0 \%)$ & $23(76.7 \%)$ & \multirow{2}{*}{$0.243^{\wedge}$} & \multirow{2}{*}{$0.390^{\wedge}$} & \multirow{2}{*}{$0.754^{\wedge}$} \\
\hline & Unmarried & $10(40.0 \%)$ & $6(20.0 \%)$ & 7 (23.3\%) & & & \\
\hline \multirow{4}{*}{ Co-morbidity } & HTN & -- & $23(76.7 \%)$ & 19 (63.3\%) & -- & -- & $0.453^{\wedge}$ \\
\hline & ISHD & -- & 15 (50.0\%) & 10 (33.3\%) & -- & -- & $0.190^{\wedge}$ \\
\hline & Old CVS & -- & 7 (23.3\%) & 4 (13.3\%) & -- & -- & $0.317^{\wedge}$ \\
\hline & COPD & -- & $12(40.0 \%)$ & $8(26.7 \%)$ & -- & -- & $0.273^{\wedge}$ \\
\hline \multirow{2}{*}{ AST (IU/L) } & Mean \pm SD & -- & $48.2 \pm 17.6$ & $49.3 \pm 25.2$ & \multirow{2}{*}{--} & \multirow{2}{*}{--} & \multirow{2}{*}{$0.802^{\#}$} \\
\hline & Range & -- & $30.0-105.0$ & $25.0-125.0$ & & & \\
\hline \multirow{2}{*}{ ALT (IU/L) } & Mean \pm SD & -- & $45.7 \pm 23.6$ & $49.4 \pm 23.9$ & \multirow{2}{*}{--} & \multirow{2}{*}{--} & \multirow{2}{*}{$0.545^{\#}$} \\
\hline & Range & -- & $20.0-127.0$ & $20.0-114.0$ & & & \\
\hline \multirow{2}{*}{ S. Albumin (g/dL) } & Mean \pm SD & -- & $2.5 \pm 0.5$ & $2.8 \pm 0.8$ & \multirow{2}{*}{--} & \multirow{2}{*}{--} & \multirow{2}{*}{$0.120^{\#}$} \\
\hline & Range & -- & $1.7-3.5$ & $1.7-5.1$ & & & \\
\hline \multirow{2}{*}{ T. Bilirubin (mg/dL) } & Mean \pm SD & -- & $1.4 \pm 0.5$ & $1.3 \pm 0.7$ & \multirow{2}{*}{--} & \multirow{2}{*}{--} & \multirow{2}{*}{$0.566^{\#}$} \\
\hline & Range & -- & $0.7-3.2$ & $0.3-2.6$ & & & \\
\hline
\end{tabular}

"P-value of independent t-test; 'P-value of chi square test; P Cn/CLD: P-value for the comparison between control and CLD groups; P Cn/HCC: P-value for the comparison between control and HCC groups; P CLD/HCC: P-value for the comparison between CLD and HCC groups.

Table 2. Comparison between study groups regarding QOL domains.

\begin{tabular}{|c|c|c|c|c|c|c|c|}
\hline Domains & Measure & $\begin{array}{l}\text { Control } \\
(\mathrm{N}=30)\end{array}$ & $\begin{array}{c}\text { CLD } \\
(\mathbf{N}=30)\end{array}$ & $\begin{array}{c}\text { HCC } \\
(\mathbf{N}=30)\end{array}$ & P Cn/CLD & P Cn/HCC & P CLD/HCC \\
\hline \multirow{2}{*}{ PF (Physical functioning) } & Mean \pm SD & $92.0 \pm 15.5$ & $33.5 \pm 28.6$ & $65.3 \pm 29.8$ & \multirow{2}{*}{$<0.001^{*}$} & \multirow{2}{*}{$<0.001^{*}$} & \multirow{2}{*}{$<0.001^{*}$} \\
\hline & Range & $20.0-100.0$ & $0.0-100.0$ & $0.0-100.0$ & & & \\
\hline \multirow{2}{*}{$\begin{array}{c}\text { RLPH (Role limitation due to } \\
\text { physical health) }\end{array}$} & Mean \pm SD & $93.3 \pm 19.6$ & $40.8 \pm 42.3$ & $57.5 \pm 49.6$ & \multirow{2}{*}{$<0.001^{*}$} & \multirow{2}{*}{$<0.001^{*}$} & \multirow{2}{*}{0.167} \\
\hline & Range & $0.0-100.0$ & $0.0-100.0$ & $0.0-100.0$ & & & \\
\hline \multirow{2}{*}{$\begin{array}{l}\text { RLEP (Role limitation due to } \\
\text { emotional problems) }\end{array}$} & Mean \pm SD & $95.6 \pm 11.5$ & $76.7 \pm 43.0$ & $80.0 \pm 40.7$ & \multirow{2}{*}{$0.026^{*}$} & \multirow{2}{*}{$0.049^{*}$} & \multirow{2}{*}{0.759} \\
\hline & Range & $66.7-100.0$ & $0.0-100.0$ & $0.0-100.0$ & & & \\
\hline \multirow{2}{*}{ EF (Energy/Fatigue) } & Mean \pm SD & $64.0 \pm 17.1$ & $35.5 \pm 23.0$ & $45.9 \pm 17.5$ & \multirow{2}{*}{$<0.001^{*}$} & \multirow{2}{*}{$<0.001^{*}$} & \multirow{2}{*}{$0.050^{*}$} \\
\hline & Range & $20.0-95.0$ & $0.0-90.0$ & $25.0-88.0$ & & & \\
\hline \multirow{2}{*}{ EW (Emotional well-being) } & Mean \pm SD & $77.6 \pm 12.2$ & $56.9 \pm 18.1$ & $61.7 \pm 15.2$ & \multirow{2}{*}{$<0.001^{*}$} & \multirow{2}{*}{$<0.001^{*}$} & \multirow{2}{*}{0.271} \\
\hline & Range & $52.0-96.0$ & $20.0-84.0$ & $28.0-96.0$ & & & \\
\hline \multirow{2}{*}{ SF (social functioning) } & Mean \pm SD & $86.3 \pm 19.0$ & $45.8 \pm 33.9$ & $72.1 \pm 19.9$ & \multirow{2}{*}{$<0.001^{*}$} & \multirow{2}{*}{$0.007^{*}$} & \multirow{2}{*}{$<0.001^{*}$} \\
\hline & Range & $50.0-100.0$ & $0.0-100.0$ & $25.0-100.0$ & & & \\
\hline \multirow{2}{*}{$\mathbf{P}$ (pain) } & Mean \pm SD & $74.6 \pm 20.7$ & $51.7 \pm 28.2$ & $62.6 \pm 27.6$ & \multirow{2}{*}{$<0.001^{*}$} & \multirow{2}{*}{0.061} & \multirow{2}{*}{0.135} \\
\hline & Range & $35.0-100.0$ & $0.0-100.0$ & $12.5-100.0$ & & & \\
\hline \multirow{2}{*}{ GH (general health) } & Mean \pm SD & $72.2 \pm 21.0$ & $38.8 \pm 15.3$ & $53.6 \pm 13.0$ & \multirow{2}{*}{$<0.001^{*}$} & \multirow{2}{*}{$<0.001^{*}$} & \multirow{2}{*}{$<0.001^{*}$} \\
\hline & Range & $30.0-100.0$ & $15.0-75.0$ & $25.0-80.0$ & & & \\
\hline \multirow{2}{*}{ Total } & Mean \pm SD & $81.9 \pm 12.4$ & $47.5 \pm 21.9$ & $62.3 \pm 16.1$ & \multirow{2}{*}{$<0.001^{*}$} & \multirow{2}{*}{$<0.001^{*}$} & \multirow{2}{*}{$0.004^{*}$} \\
\hline & Range & $45.3-97.1$ & $7.4-87.6$ & $27.7-88.4$ & & & \\
\hline
\end{tabular}

"P-value of independent t-test; "Significant; P Cn/CLD: P-value for the comparison between control and CLD groups; P Cn/HCC: P-value for the comparison between control and HCC groups; P CLD/HCC: P-value for the comparison between CLD and HCC groups. 
There were significant positive correlation between age and EW domain among CLD group. There were significant positive correlation between serum albumin and PF, EF, SF domains and total score (Table 3 and Figure 2).

\section{Discussion}

QOL analysis is now an integral outcome measure in many diseases including CLD and HCC. As awareness grows of the QOL decrement from CLD and HCC, and their clinical consequences, investigators have become progressively interested in measuring QOL in clinical trials. This acknowledgment that the burden of hepatic diseases extends beyond its economic impact coincides with recommendations by the National Institutes of Health to conduct studies that measure not only traditional biological outcomes in HCV (i.e., HCV RNA, liver enzyme levels, liver histology), but also patient-oriented outcomes [28].

Table 3. Correlation between QOL and age, AST, ALT, albumin \& bilirubin among study groups.

\begin{tabular}{|c|c|c|c|c|c|c|c|c|c|c|c|c|}
\hline \multirow[b]{2}{*}{ Domain } & \multirow[b]{2}{*}{ Measure } & \multicolumn{3}{|c|}{ Age } & \multicolumn{2}{|c|}{ AST } & \multicolumn{2}{|c|}{ ALT } & \multicolumn{2}{|c|}{ Albumin } & \multicolumn{2}{|c|}{ Bilirubin } \\
\hline & & $\begin{array}{l}\text { Control } \\
(\mathrm{N}=\mathbf{3 0})\end{array}$ & $\begin{array}{c}\text { CLD } \\
(\mathrm{N}=\mathbf{3 0})\end{array}$ & $\begin{array}{c}\text { HCC } \\
(\mathrm{N}=\mathbf{3 0})\end{array}$ & $\begin{array}{c}\text { CLD } \\
(\mathrm{N}=30)\end{array}$ & $\begin{array}{c}\text { HCC } \\
(\mathrm{N}=30)\end{array}$ & $\begin{array}{c}\text { CLD } \\
(\mathrm{N}=30)\end{array}$ & $\begin{array}{c}\text { HCC } \\
(\mathrm{N}=30)\end{array}$ & $\begin{array}{c}\text { CLD } \\
(\mathrm{N}=30)\end{array}$ & $\begin{array}{c}\text { HCC } \\
(\mathrm{N}=30)\end{array}$ & $\begin{array}{c}\text { CLD } \\
(\mathrm{N}=30)\end{array}$ & $\begin{array}{c}\text { HCC } \\
(\mathrm{N}=30)\end{array}$ \\
\hline \multirow{2}{*}{ PF } & $\mathbf{r}$ & 0.015 & 0.107 & -0.144 & -0.185 & 0.197 & -0.113 & 0.144 & 0.384 & 0.087 & -0.169 & 0.017 \\
\hline & $\mathbf{p}$ & 0.936 & 0.573 & 0.449 & 0.327 & 0.297 & 0.551 & 0.449 & $0.036^{*}$ & 0.649 & 0.373 & 0.929 \\
\hline \multirow{2}{*}{ RLPH } & $\mathbf{r}$ & 0.240 & 0.211 & 0.120 & -0.054 & 0.101 & 0.022 & -0.103 & 0.322 & 0.074 & -0.014 & -0.151 \\
\hline & $\mathbf{P}$ & 0.202 & 0.262 & 0.527 & 0.778 & 0.595 & 0.908 & 0.589 & 0.083 & 0.697 & 0.943 & 0.426 \\
\hline \multirow{2}{*}{ RLEP } & $\mathbf{r}$ & -0.224 & 0.242 & -0.003 & -0.079 & 0.095 & -0.130 & 0.086 & 0.212 & 0.259 & 0.285 & 0.221 \\
\hline & $\mathbf{P}$ & 0.235 & 0.197 & 0.988 & 0.678 & 0.617 & 0.492 & 0.650 & 0.261 & 0.167 & 0.127 & 0.241 \\
\hline \multirow{2}{*}{$\mathbf{E F}$} & $\mathbf{r}$ & 0.053 & 0.066 & -0.009 & -0.170 & -0.075 & -0.045 & -0.116 & 0.469 & 0.247 & 0.026 & 0.087 \\
\hline & $\mathbf{P}$ & 0.780 & 0.729 & 0.963 & 0.369 & 0.692 & 0.813 & 0.541 & $0.009^{*}$ & 0.188 & 0.891 & 0.649 \\
\hline \multirow{2}{*}{ EW } & $\mathbf{r}$ & 0.102 & 0.381 & 0.242 & 0.074 & 0.263 & 0.113 & 0.112 & 0.232 & 0.276 & -0.106 & -0.220 \\
\hline & $\mathbf{P}$ & 0.591 & $0.038^{*}$ & 0.198 & 0.697 & 0.160 & 0.553 & 0.556 & 0.217 & 0.140 & 0.578 & 0.242 \\
\hline \multirow{2}{*}{ SF } & $\mathbf{r}$ & -0.279 & 0.139 & -0.301 & -0.225 & 0.116 & -0.151 & 0.107 & 0.447 & 0.075 & 0.028 & -0.017 \\
\hline & $\mathbf{P}$ & 0.136 & 0.464 & 0.106 & 0.232 & 0.542 & 0.425 & 0.574 & $0.013^{*}$ & 0.695 & 0.885 & 0.927 \\
\hline \multirow{2}{*}{$\mathbf{P}$} & $\mathbf{r}$ & -0.086 & 0.062 & 0.163 & -0.415 & -0.242 & -0.305 & -0.172 & 0.112 & 0.190 & 0.015 & 0.049 \\
\hline & $\mathbf{P}$ & 0.653 & 0.744 & 0.390 & 0.023 & 0.198 & 0.102 & 0.364 & 0.555 & 0.314 & 0.937 & 0.797 \\
\hline \multirow{2}{*}{ GH } & $\mathbf{r}$ & -0.238 & 0.080 & 0.241 & -0.054 & -0.047 & 0.007 & -0.106 & 0.308 & -0.031 & -0.146 & -0.182 \\
\hline & $\mathbf{P}$ & 0.205 & 0.674 & 0.200 & 0.777 & 0.804 & 0.973 & 0.579 & 0.098 & 0.872 & 0.441 & 0.335 \\
\hline \multirow{2}{*}{ Total } & $\mathbf{r}$ & -0.076 & 0.219 & 0.052 & -0.192 & 0.097 & -0.117 & -0.013 & 0.408 & 0.245 & 0.027 & -0.009 \\
\hline & $\mathbf{P}$ & 0.689 & 0.244 & 0.784 & 0.310 & 0.612 & 0.538 & 0.947 & $0.025^{*}$ & 0.192 & 0.889 & 0.961 \\
\hline
\end{tabular}

*Significant.

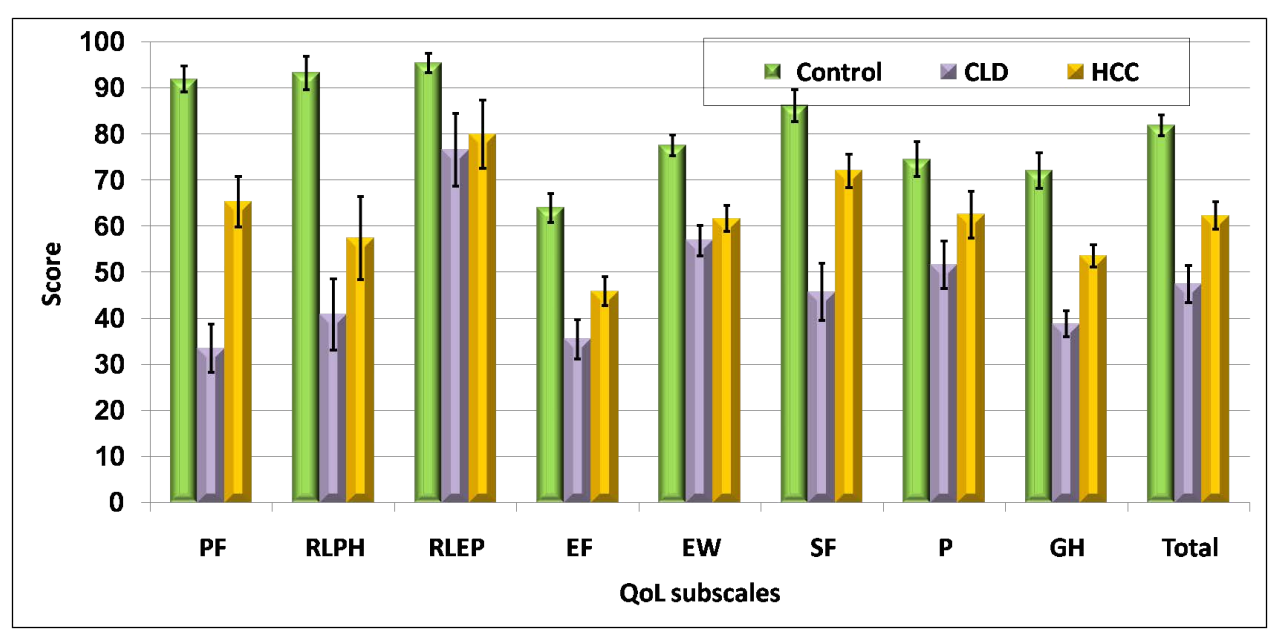

Figure 1. Comparison between study groups regarding QOL domains. 


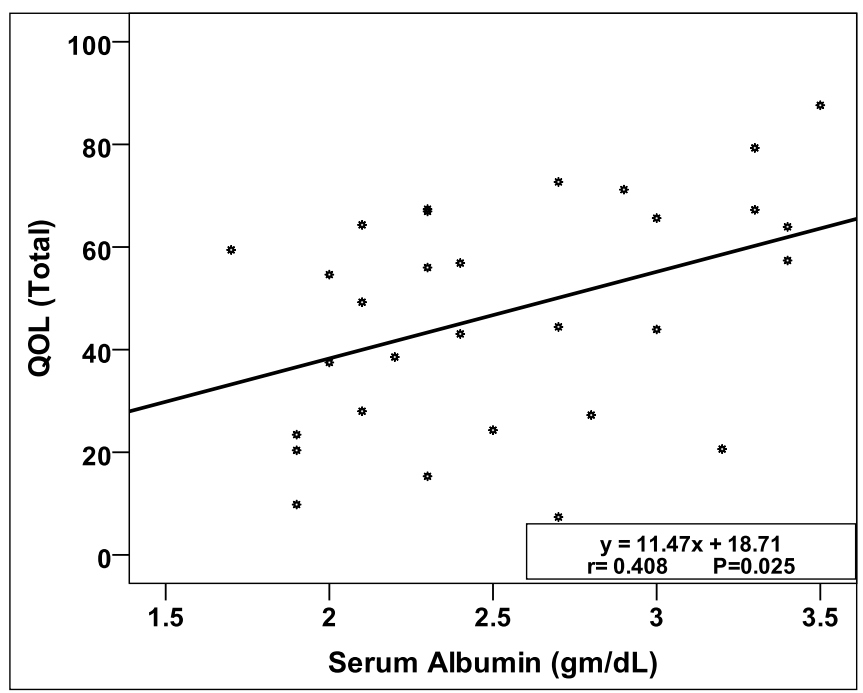

Figure 2. Correlation between serum albumin and QOL domains.

Our study showed that all QOL domains were statistically significant lower among CLD group versus control group in all eight scales and summary scores. Our results coincides with 3 studies that compared HRQOL in HCV-seropositive patients versus healthy controls without HCV, revealing that the largest impact of HCV was in the role-physical scale (RLEF), followed by the role-emotional scale (RLEP) and the general health scale (GH) [29]-[31].

More studies reported that CLD patients' HRQOL was worse than non-CLD patients, with CLD patients showing significantly lower SF-36 scores in six domains, especially in the VT (EF = energy/fatigue), GH (general health), and RLEP ( role limitation due to emotional problems) scales [32]-[34].

While only one study by Schwarzinger et al. 2004 revealed that the HRQOL of untreated CLD patients resembles the general population and this result may be because it was done among a population whose serological status is unknown to patients (they have HCV chronic infection as defined by positive tests for anti-HCV antibody and HCV-RNA but lack of knowledge of their serological status may have improved their HRQOL) [35].

Our study revealed that all QOL domains were statistically significant lower among HCC group versus control group in all eight scales and summary scores. Our results coincide with Kondo et al. (2007), Steel et al. (2007) and Lee et al. (2007). They found that patients with HCC had lower HRQOL than the general population, especially in physical [36]-[38], psychological [36] [37] and functional well-being [36] [37].

In contrast, some studies reported better scores in social/family well-being [37] and the environment subscale [38]. The difference here is mainly because they used different measures to assess Health-Related Quality of Life. Steel et al. (2007) used FACT-Hep where Lee et al. (2007) used EORTC QLQ-C30. Patients in the second study received treatment in form of resection. None of our patients in the HCC samples were actively receiving treatments for the HCC.

Gandhi et al. (2014) [39] conducted a review of literature on all the studies published in the last 13 years assessing QOL in patients with HCC as a primary or secondary end point. He identified three studies assessing HRQOL in HCC using the generic questionnaire SF-36. The three studies used HRQOL as primary endpoint and These QOL indicators are significantly impaired in HCC patients [17] [36] [40]. Two of the three studies were post-surgery or post-liver directed therapy [36] [40].

In this study, all QOL domains were lower among CLD group versus HCC group in all eight scales and summary scores. The differences were statistically significant in $\mathrm{PF}=$ physical functioning, $\mathrm{EF}=$ energy/fatigue or vitality, $\mathrm{SF}=$ social functioning and GH = general health but not in subscales of RLPH $=$ role limitation due to physical health, RLEP = role limitation due to emotional problems, EW = emotional well-being and $\mathrm{P}=\mathrm{Bo}-$ dily Pain. Our results agree with Casanovas et al. (2010) [41] who found that HCV (without CLD) was associated with worse HRQOL on most of the LDQOL disease-specific dimensions than HCC. Although these differences were only statistically significant on four dimensions (symptoms, effects of liver disease, concentration, and sleep), we are nevertheless in line with this results. 
One study found no difference [36]. Kondo and his colleagues 2007 assessed 97 patients with HCC who had been treated successfully with percutaneous ablation therapy, and 97 patients with CLD without HCC matched for age and sex, using the Japanese version of Short-Form 36. He found that HRQOL was lower in both groups than in the general population. Patients with HCC and patients in the control group showed similar scores. By multivariate analysis, liver function, especially serum albumin, strongly predicted health-related quality of life, and concluded that impaired health-related quality of life was not associated with the presence of HCC but dependent on the level of liver function. He did not specify the cause of CLD status in his sample.

We should state also that some other studies disagree with us like Bianchi et al. (2003) who found that when HCC patients on top of cirrhosis were compared with matched cirrhotics. Patients with HCC had worse physical well-being and overall HRQOL than patients with CLD, mainly in terms of P = Bodily Pain, RLPH = Role Limitation-Physical, and PF = the Physical Component Summary of Short Form-36, as well as Pain of Nottingham Health Profile [17]. Our HCC patients were with compensated cirrhosis which explains better scores on HRQOL. Also Steel et al. (2007) who found that people diagnosed with HCC, prior to treatment, had a poorer overall HRQOL when compared to those persons with CLD and the general population. They used a different scale A sociodemographic questionnaire and the Functional Assessment of Cancer Therapy-Hepatobiliary (FACT-Hep) which is a disease specific questionnaire [37].

Despite the many studies that have shown a reduced HRQOL in hepatology, relatively few studies have investigated which factors influence liver patients' HRQOL. That is a problem when we want to move from just measuring HRQOL towards treatments that improve HRQOL. Traditional markers of liver disease severity include histological activity (e.g., Knodell scores), biochemical activity (e.g., ALT levels), and clinical activity (e.g., Child's class, MELD score).

In the present study, we included biochemical activity. We tried to find out if liver functions affected HRQOL. Transaminases and bilirubin have no relation to individual and sum score of SF36 while albumin has a significant relationship with two subscores $(\mathrm{EF}, \mathrm{SF})$ and with the sum score also (P value $<0.05)$. These findings were supported by other colleagues, [36] [42] who found that patients with higher albumin had better HRQOL. Ueno et al. (2002) [43] found that lower serum transaminases levels had better HRQOL but Spiegel et al. (2005) did not find such relation [11].

As regard gender effect, it was minor in diseases groups (HCC/CLD), only males had significantly higher PF among HCC group. As regard age and its effect on HRQOL, there were significant positive correlation between age and EW domain among CLD group. We agreed with Spiegel et al. (2005), who found that age and sex do not seem to play a role in HRQOL changes [11].

The study had some limitations. Firstly, assessment of QOL in cancer patients was optimally performed with a combination of a generic questionnaire and a disease-specific questionnaire to ensure that common problems were uniformly detected and reported as well as specific issues related to disease site and treatment. A disadvantage was that generic instruments were not designed to identify disease-specific domains that might be important to establish clinical changes [44]. It should also be noted that at least some of the impact on HRQOL was likely to be due to the underlying cirrhosis rather than the tumor itself, which tended to be asymptomatic. The questionnaire was administered by interview and the results might differ if the questionnaire was self-administered. A limitation of the study was the small sample size, as we only recruited 60 age- and gender-matched CLD patients without antiviral therapy as an additional control group. Finally, we were not able to examine the instrument's sensitivity to change as these are results from a cross-sectional study.

\section{Conclusion and Recommendation}

HRQOL questionnaires potentially play a significant role in bringing the patient's voice to evidence based health care. Our study showed a decrease in the QOL of Egyptian CLD patients and HCC patients compared with Egyptian population norms. The results showed that CLD were more affected than HCC patients. This had a particularly serious negative impact on their life. The findings indicate a need for updated counseling and educational materials designed to provide adequate information and consistent healthcare service to this patient setting. When communication with the physician encompasses both physical and psychosocial issues, patients have better treatment compliance, are more satisfied with the consultation and report less symptoms. Active assessment and timely healthcare interventions could improve the standard management plans as well as patient's quality of life. Enhanced awareness and understanding of patients' needs will ensure better healthcare for CLD and HCC patients in Egypt. 


\section{Acknowledgements}

We acknowledge the study participants for their gracious help.

\section{Conflict of Interest}

No conflict of interest has been declared by the authors.

\section{References}

[1] Bergner, M. (1989) Quality of Life, Health Status and Clinical Research. Medical Care, 27, S148-S156. http://dx.doi.org/10.1097/00005650-198903001-00012

[2] Testa, M. and Simonson, D. (1996) Assessment of Quality-of-Life Outcomes. New England Journal of Medicine, 334, 835-840. http://dx.doi.org/10.1056/NEJM199603283341306

[3] Wilson, I. and Cleary, P. (1995) Linking Clinical Variables with Health-Related Quality of Life: A Conceptual Model of Patient Outcomes. JAMA, 273, 59-65. http://dx.doi.org/10.1001/jama.1995.03520250075037

[4] Addington-Hall, J. and Kalra, L. (2001) Who Should Measure Quality of Life? BMJ, 322, 1417-1420. http://dx.doi.org/10.1136/bmj.322.7299.1417

[5] Marchesini, G., Bianchi, G., Amodio, P., Salerno, F., Merli, M., Panella, C., et al. (2001) Factors Associated with Poor Health-Related Quality of Life of Patients with Cirrhosis. Gastroenterology, 120, 170-178. http://dx.doi.org/10.1053/gast.2001.21193

[6] Younossi, Z.M. and Guyatt, G. (1998) Quality-of-Life Assessments and Chronic Liver Disease. The American Journal of Gastroenterology, 93, 1037-1041. http://dx.doi.org/10.1111/j.1572-0241.1998.00325.x

[7] Foster, G.R., Goldin, R.D. and Thomas, H.C. (1998) Chronic Hepatitis C Virus Infection Causes a Significant Reduction in Quality of Life in the Absence of Cirrhosis. Hepatology, 27, 209-212. http://dx.doi.org/10.1002/hep.510270132

[8] Cordoba, J., Flavia, M., Jacas, C., Sauleda, S., Esteban, J.I., Vargas, V., et al. (2003) Quality of Life and Cognitive Function in Hepatitis C at Different Stages of Liver Disease. Journal of Hepatology, 39, 231-238. http://dx.doi.org/10.1016/S0168-8278(03)00189-2

[9] Poupon, R.E., Chretien, Y., Chazouilleres, O., Poupon, R., Chwalow, J. and the French-PBC Study Group (2004) Quality of Life in Patients with Primary Biliary Cirrhosis. Hepatology, 40, 489-494. http://dx.doi.org/10.1002/hep.20276

[10] Bonkovsky, H.L., Woolley, J.M. and the Consensus Interferon Study Group (1999) Reduction of Health-Related Quality of Life in Chronic Hepatitis C and Improvement with Interferon Therapy. Hepatology, 29, 264-270. http://dx.doi.org/10.1002/hep.510290124

[11] Spiegel, B.M.R., Younossi, Z.M., Hays, R.D., Revicki, D., Robbins, S. and Kanwal, F. (2005) Impact of Hepatitis C on Health-Related Quality of Life: A Systematic Review and Quantitative Assessment. Hepatology, 41, 790-800. http://dx.doi.org/10.1002/hep.20659

[12] Svirtlih, N., Pavic, S., Terzic, D., Delic, D., Simonovic, J., Gvozdenovic, E., et al. (2008) Reduced Quality of Life in Patients with Chronic Viral Liver Disease as Assessed by SF12 Questionnaire. Journal of Gastrointestinal and Liver Diseases, 17, 405-409.

[13] Parkin, D.M., Bray, F., Ferlay, J. and Pisani, P. (2005) Global Cancer Statistics, 2002. CA: A Cancer Journal for Clinicians, 55, 74-108. http://dx.doi.org/10.3322/canjclin.55.2.74

[14] El-Serag, H.B., Marrero, J.A., Rudolph, L. and Reddy, K.R. (2008) Diagnosis and Treatment of Hepatocellular Carcinoma. Gastroenterology, 134, 1752-1763. http://dx.doi.org/10.1053/j.gastro.2008.02.090

[15] El-Serag, H.B., Davila, J.A., Petersen, N.J. and McGlynn, K.A. (2003) The Continuing Increase in the Incidence of Hepatocellular Carcinoma in the United States: An Update. Annals of Internal Medicine, 139, 817-823. http://dx.doi.org/10.7326/0003-4819-139-10-200311180-00009

[16] Kiyosawa, K., Umemura, T., Ichijo, T., Matsumoto, A., Yoshizawa, K., Gad, A. and Tanaka, E. (2004) Hepatocellular Carcinoma: Recent Trends in Japan. Gastroenterology, 127, S17-S26. http://dx.doi.org/10.1053/j.gastro.2004.09.012

[17] Bianchi, G., Loguercio, C., Sgarbi, D., Abbiati, R., Brunetti, N., De Simone, T., Zoli, M. and Marchesini, G. (2003) Reduced Quality of Life of Patients with Hepatocellular Carcinoma. Digestive and Liver Disease, 35, 46-54. http://dx.doi.org/10.1016/S1590-8658(02)00011-7

[18] Poon, R.T.P., Fan, S.T., Yu, W.C., Lam, B.K.Y., Chan, F.Y.S. and Wong, J. (2001) A Prospective Longitudinal Study of Quality of Life after Resection of Hepatocellular Carcinoma. Archives of Surgery, 136, 693-699.

http://dx.doi.org/10.1001/archsurg.136.6.693 
[19] Tanabe, G., Ueno, S., Maemura, M., Kihara, K., Aoki, D., Yoshidome, S., et al. (2001) Favorable Quality of Life after Repeat Hepatic Resection for Recurrent Hepatocellular Carcinoma. Hepato-Gastroenterology, 48, 506-510.

[20] Fan, S.-Y., Eiser, C. and Ho, M.-C. (2010) Health-Related Quality of Life in Patients with Hepatocellular Carcinoma: A Systematic Review. Clinical Gastroenterology and Hepatology, 8, 559-564. http://dx.doi.org/10.1016/j.cgh.2010.03.008

[21] European Association for the Study of the Liver (2009) EASL Clinical Practice Guidelines: Management of Chronic Hepatitis B. Journal of Hepatology, 50, 227-242. http://dx.doi.org/10.1016/j.jhep.2008.10.001

[22] Cabrera, R. and Nelson, D.R. (2010) Review Article: The Management of Hepatocellular Carcinoma. Alimentary Pharmacology \& Therapeutics, 31, 461-476. http://dx.doi.org/10.1111/j.1365-2036.2009.04200.x

[23] Ware, J.E. and Sherbourne, C.D. (1992) The MOS 36-Item Short-Form Health Survey (SF-36): I. Conceptual Framework and Item Selection. Medical Care, 30, 473-483. http://dx.doi.org/10.1097/00005650-199206000-00002

[24] Hays, R.D. and Shapiro, M.F. (1992) An Overview of Generic Health-Related Quality of Life Measures For HIV Research. Quality of Life Research, 1, 91-97. http://dx.doi.org/10.1007/BF00439716

[25] Stewart, A.L., Sherbourne, C., Hays, R.D., Wells, K.B., Nelson, E.C., Kamberg, C., et al. (1992) Summary and Discussion of MOS Measures. In: Stewart, A.L. and Ware, J.E., Eds., Measuring Functioning and Well-Being: The Medical Outcome Study Approach, Duke University Press, Durham, 345-371.

[26] Al Abdulmohsin, S.A., Coons, S., Draugalis, J.L.R. and Hays, R.D. (1998) Reliability of an Arabic Version of the RAND-36 Health Survey and Its Equivalence to the US-English Version. Medical Care, 36, 428-432. http://dx.doi.org/10.1097/00005650-199803000-00018

[27] Meenakshi, J., Winston, S. and Joel A.B. (2014) Health and Quality of Life Outcomes. Health and Quality of Life Outcomes, 12,173. http://dx.doi.org/10.1186/s12955-014-0173-5

[28] Seeff, L.B. and Hoofnagle, J.H. (2002) National Institutes of Health Consensus Development Conference: Management of Hepatitis C. Hepatology, 36, S1-S2. http://dx.doi.org/10.1002/hep.1840360702

[29] Hussain, K.B., Fontana, R.J., Moyer, C.A., Su, G.L., Sneed-Pee, N. and Lok, A.S. (2001) Comorbid Illness Is an Important Determinant of Health-Related Quality of Life in Patients with Chronic Hepatitis C. The American Journal of Gastroenterology, 96, 2737-2744. http://dx.doi.org/10.1111/j.1572-0241.2001.04133.x

[30] Gifford, S.M., O’Brien, M.L., Bammer, G., Banwell, C. and Stoove, M. (2003) Australian Women’s Experiences of Living with Hepatitis C Virus: Results from a Cross-Sectional Survey. Journal of Gastroenterology and Hepatology, 18, 841-850. http://dx.doi.org/10.1046/j.1440-1746.2003.03077.x

[31] Fleming, C.A., Christiansen, D., Nuñes, D., Heeren, T., Thornton, D., Horsburgh Jr., C.R., et al. (2004) Health-Related Quality of Life of Patients with HIV Disease: Impact of Hepatitis C Coinfection. Clinical Infectious Diseases, 38, 572578. http://dx.doi.org/10.1086/381263

[32] Björnsson, E., Verbaan, H., Oksanen, A., Frydén, A., Johansson, J., Friberg, S., et al. (2009) Health-Related Quality of Life in Patients with Different Stages of Liver Disease Induced by Hepatitis C. Scandinavian Journal of Gastroenterology, 44, 878-887. http://dx.doi.org/10.1080/00365520902898135

[33] Kwan, J.W., Cronkite, R.C., Yiu, A., Goldstein, M.K., Kazis, L. and Cheung, R.C. (2008) The Impact of Chronic C and Co-Morbid Illnesses on Health-Related Quality of Life. Quality of Life Research, 17, 715-724. http://dx.doi.org/10.1007/s11136-008-9344-3

[34] Kang, S., Hwang, S., Lee, S., Chang, F. and Lee, S. (2005) Health-Related Quality of Life and Impact of Antiviral Treatment in Chinese Patients with Chronic Hepatitis C in Taiwan. World Journal of Gastroenterology, 11, 7494-7498. http://dx.doi.org/10.3748/wjg.v11.i47.7494

[35] Schwarzinger, M., Dewedar, S., Rekacewicz, C., Elaziz, K.M.A., Fontanet, A., Carrat, F. and Mohamed, M.K. (2004) Chronic Hepatitis C Virus Infection: Does It Really Impact Health-Related Quality of Life? A Study in Rural Egypt. Hepatology, 40, 1434-1441. http://dx.doi.org/10.1002/hep.20468

[36] Kondo, Y., Yoshida, H., Tateishi, R., Shiina, S., Mine, N., Yamashiki, N., et al. (2007) Health-Related Quality of Life of Chronic Liver Disease Patients with and without Hepatocellular Carcinoma. Journal of Gastroenterology and Hepatology, 22, 197-203. http://dx.doi.org/10.1111/j.1440-1746.2006.04456.x

[37] Steel, J.L., Chopra, K., Olek, M.C. and Carr, B.I. (2007) Health-Related Quality of Life: Hepatocellular Carcinoma, Chronic Liver Disease, and the General Population. Quality of Life Research, 16, 203-215. http://dx.doi.org/10.1007/s11136-006-9111-2

[38] Lee, L.J., Chen, C.H., Yao, G., Chung, C.W., Sheu, J.C., Lee, P.H., et al. (2007) Quality of Life in Patients with Hepatocellular Carcinoma Received Surgical Resection. Journal of Surgical Oncology, 95, 34-39. http://dx.doi.org/10.1002/jso.20374

[39] Gandhi, S., Khubchandani, S. and Iyer, R. (2014) Quality of Life and Hepatocellular Carcinoma. Journal of Gastrointestinal Oncology, 5, 296-317. 
[40] Wible, B.C., Rilling, W.S., Drescher, P., Hieb, R.A., Saeian, K., Frangakis, C., et al. (2010) Longitudinal Quality of Life Assessment of Patients with Hepatocellular Carcinoma after Primary Transarterial Chemoembolization. Journal of Vascular and Interventional Radiology, 21, 1024-1030. http://dx.doi.org/10.1016/j.jvir.2010.03.005

[41] Casanovas, T., Jané, L., Herdman, M., Casado, A., Garcia, B., Prat, B. and Fabregat, J. (2010) Assessing Outcomes in Liver Disease Patients: Reliability and Validity of the Spanish Version of the Liver Disease Quality of Life Questionnaire. Value in Health, 13, 455-462. http://dx.doi.org/10.1111/j.1524-4733.2009.00688.x

[42] Shun, S.C., Chiou, J.F., Lai, Y.H., Yu, P.J., Wei, L.L., Tsai, J.T., et al. (2008) Changes in Quality of Life and Its Related Factors in Liver Cancer Patients Receiving Stereotactic Radiation Therapy. Supportive Care in Cancer, 16, 10591065. http://dx.doi.org/10.1007/s00520-007-0384-y

[43] Ueno, S., Tanabe, G., Nuruki, K., Yoshidome, S., Kubo, F., Kihara, K., et al. (2002) Quality of Life after Hepatectomy in Patients with Hepatocellular Carcinoma: Implication of Change in Hepatic Protein Synthesis. Hepato-Gastroenterology, 49, 492-496.

[44] Jenneya, M. and Campbellb, S. (1997) Measuring Quality of Life. Archives of Disease in Childhood, 77, $347-350$. http://dx.doi.org/10.1136/adc.77.4.347 